\title{
Erratum to: Effect of seasonal variations of organic loading rate and acid phase on methane yield of food waste leachate in South Korea
}

\author{
Dong Jin Lee ${ }^{1} \cdot \mathrm{Ji} \mathrm{Su} \mathrm{Bae}^{1} \cdot$ Dong Cheol Seo ${ }^{2}$
}

Published online: 28 April 2017

CC The Korean Society for Applied Biological Chemistry 2017

\section{Erratum to: Appl Biol Chem (2017) 60(1):87-93 DOI 10.1007/s13765-017-0253-4}

Young Man Yoon and Ik Won Choi, who were included in the author group of the originally published article, are now removed because it was found that they have not participated in and contributed sufficiently to the article. Hence, the corresponding author and these two authors agree that their names be removed from the article. The updated author group is shown in this erratum.

The online version of the original article can be found under doi:10.1007/s13765-017-0253-4.

Ji Su Bae

jisubae88@gmail.com

$\bowtie$ Dong Cheol Seo

drseodc@gmail.com

1 Environmental Resources Research Department, National Institute of Environmental Research, Environmental Research Complex, Incheon 404-708, Republic of Korea

2 Division of Applied Life Science (BK21 Plus) \& Institute of Agriculture and Life Science, Gyeongsang National University, Jinju 52828, Republic of Korea 